
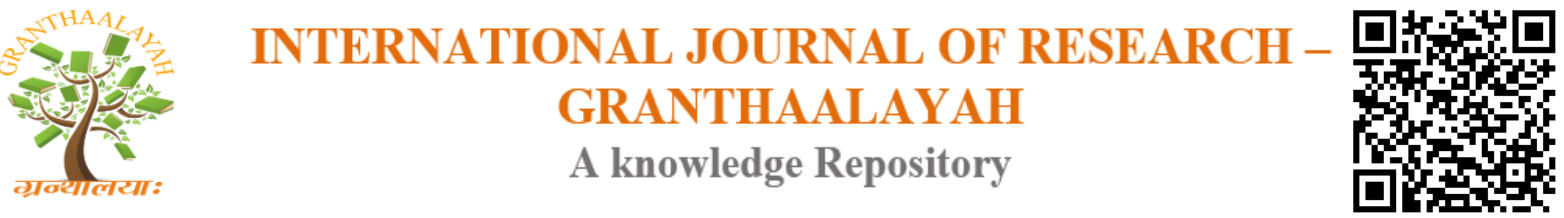

Science

\title{
INF $\gamma$, TNFa, IL-6 LEVELS IN THE PERIPHERAL BLOOD SERUM IN DIFFERENT CLINICAL COURSES OF NONSPECIFIC VULVOVAGINITIS IN ADOLESCENT GIRLS
}

\author{
Smailova Lazat Kenzhebekovna ${ }^{1}$, Bilalova Gulshat Tursunovna ${ }^{2}$, Kurmanova Almagul \\ Medeubaeva $^{3}$ \\ 1,2 JSC, Astana Medical University, Republic of Kazakhstan, Astana \\ ${ }^{3}$ Doctor of Medical Sciences, Professor Scientific Center of Obstetrics, Gynecology and \\ Perinatology of the Ministry of Health of the Republic of Kazakhstan, Almaty
}

\begin{abstract}
The conducted study showed that increased production of anti-inflammatory INF $\gamma$ cytokine is observed in girls and adolescents with acute nonspecific vulvovaginitis compared to the subacute course of the disease, though no adequately high production of this cytokine is practically observed in both cases. The obtained data indicate the suppression of both the cell and humoral anti-inflammatory immunity. IL-6 is responsible for the specificity and the adequacy of immunological reactions. This fact is connected primarily with the presence of multidirectional pathological changes in the immunity system.
\end{abstract}

Keywords: Adolescent Girl; Vulvovaginitis; Immunity; Cytokines.

Cite This Article: Smailova Lazat Kenzhebekovna, Bilalova Gulshat Tursunovna, and Kurmanova Almagul Medeubaeva. (2017). "INF $\gamma$, TNF $\alpha$, IL-6 LEVELS IN THE PERIPHERAL BLOOD SERUM IN DIFFERENT CLINICAL COURSES OF NONSPECIFIC VULVOVAGINITIS IN ADOLESCENT GIRLS." International Journal of Research Granthaalayah, 5(7), 408-416. https://doi.org/10.29121/granthaalayah.v5.i7.2017.2147.

\section{Introduction}

According to the researchers of this problem, vulvovaginitis in not sexually active girls and adolescents is found in 63 to $83 \%$ [1], more than $60 \%$ suffer from the recurrent form of the disease [2-5].

According to studies, chronic vulvovaginitis is found in $48.1 \%$ of girls during preventive medical examination, and in $29.8 \%$ of girls when they seek medical advice of a gynecologist [6]. The majority of researchers note the absence of clear differentiation between acute and chronic vulvovaginitis, but a low therapeutic effect is noticed which may indicate a higher percentage of chronic progression of the disease. 
As a rule, transition of vulvovaginitis into chronic and recurrent state is connected with inadequately administered therapy, peculiarities of the infectant, decrease in immune reactivity of the body, including local immunity [2].

Studies of immunological aspects of inflammatory disease development mechanisms speak about the key role of imbalance in the system of subpopulations of Th1/Th2-lymphocytes mediated by cytokines $[7,8,9]$.

The study of cytokines and their role in regulation of the immune response determine the value of their research in various pathological processes, including various inflammatory processes in female genital organs $[10,11]$.

The study of the immunity system under conditions of nonspecific vulvovaginitis is due to the fact that any immune imbalance leads to development of a disease, contributes to development of complications, chronicity and recurrence of the process.

The studies carried out on the quantity of cytokines in the serum, in the plasma, the vaginal content during vulvovaginitis are very contradictory $[12,13]$.

It is necessary to note the importance of determination of cytokine concentration in vulvovaginitis as well as changes in the disease treatment dynamics [14].

In the process of inflammation, cytokines are involved almost in every link of the immune response, including differentiation of predecessors of immune system cells.

Monocytes, T- and B-lymphocytes, mast cells and a number of cytokines participate in an inflammatory process.

In practice, a cytokine status study allows to evaluate the nature of an inflammatory process and forecast the outcome of a disease, to objectively evaluate the efficiency of treatment, especially in case of using immune drugs.

TNF $\alpha$, IL-1, IL -6, IL-8, IL-12 to which anti-inflammatory cytokines IL-4, IL-10, IL-11, IL-13 oppose are of paramount importance among anti-inflammatory cytokines.

The highest level of emphasis is given to IL-6 as an anti-inflammatory factor in development of inflammation.

IL-6 is a factor of growth and differentiation of B-lymphocytes, an activator of polyclonal production of immunoglobulins, it supports proliferation of T-cells, is one of the mediators of acute inflammation phase reactions. It is known that IL-6 is produced by macrophages, monocytes, fibroblasts, lymphocytes, as well as endothelium cells and ensures an immune inflammatory response.

It contributes to the chronicity of acute and aggravated chronic inflammatory processes. 
IL-6 finishes the development of an inflammatory reaction, secreted later as IL-1 and TNF $\alpha$, suppresses their production, and they encourage its formation.

$\mathrm{TNF} \alpha$ is an anti-inflammatory cytokine, one of the main mediators of an inflammatory process and activation of leukocytes, induces the expression of adhesion and chemokine molecules on endothelium, stimulates the production of IL-1, IL-6, IL-8, IFN $\gamma$.

$\mathrm{TNF} \alpha$ is produced by monocytes/macrophages, endothelial and mast cells, and resembles IL-1 and IL- 6 in terms of the range of target cells and biological effects.

The cytotoxic action of TNF $\alpha$ is that it causes generalization of active forms of oxygen, superoxide radicals, nitrogen oxide in the cell membrane due to its ability to induce apoptosis.

In addition, TNF $\alpha$ has the ability to influence the endothelium by intensifying the expression of adhesive molecules and activates pacrophages, neutrophils, increases the secretion of prostaglandins, has a chemotactic effect on different cells and determines the synthesis of proteins in the acute phase of inflammation.

In the light of modern understanding of molecular mechanisms of immune reactions, special attention is paid to IFN $\gamma$, a regulatory cytokine of the immune response.

The main action of IFN $\gamma$ is participation in reactions of the immune system. It starts to be produced at subsequent stages of an inflammation process by already sensibilized T-lymphocytes and actively participates in a cascade of the specific immune response.

Thus, the diagnostic significance of evaluation of the level of cytokine concentration is to determine whether it increases or decreases to evaluate the severity and forecast the course of a disease, and it is advisable to determine the cytokine concentration in the course of treatment to evaluate the effectiveness of such treatment, to optimize the immune therapy and forecast the criterion of development of the infectious and inflammatory process [15].

The modern strategy of using cytokines as immune therapy in clinical medicine is based on the above. Determination of the immune and cytokine status in different courses of nonspecific vulvovaginitis in adolescent girls will help to better understand the disease and make decisions concerning the advisability of the immune system correction.

\subsection{Goal of the Research}

To establish pathogenetic informativeness about the concentration of INF $\gamma$, TNF $\alpha$ and IL-6 cytokines in the blood serum in adolescent girls in different clinical courses of nonspecific vulvovaginitis with the purpose of optimization of diagnostics, better understanding and decision-making about the advisability of immune system correction and rehabilitation and preventive measures. 


\subsection{Objectives of the Research}

Determination of the INF $\gamma, \mathrm{TNF} \alpha$ and IL-6 cytokine concentration for the purpose of better understanding and decision-making about the advisability of immune system correction in different clinical courses of nonspecific vulvovaginitis in adolescent girls.

\section{Research Methods and Materials}

The clinical examination stage included a questionnaire survey, collection of complaints and medical history, gynecological examination, microbiological study of the vaginal secretion (bacterioscopic and bacteriological study), ELISA blood analysis for sexually transmitted infections, immunological status, determination of INF $\gamma$, TNF $\alpha$, IL-6 cytokines in the peripheral blood serum, evaluation of the phagocytic activity of vaginal secretion neutrophilic leukocytes, vaginoscopy, transabdominal ultrasound of the pelvis.

Anamnestic data of the patients were studied and analyzed from child's development records (form No. 112/U), child's medical records (form No. 26/U), case records (form No. 35/U), dispensary observation records (form No. 30/U).

To exclude specific vulvovaginitis pathogens - analysis for sexually transmitted infections. Microbiological (bacterioscopic and bacteriological) study of the vaginal secretion was conducted in the Almaty dermatovenerologic dispensary.

The quantitative study of the main populations and subpopulations of lymphocytes was conducted in the immunologic laboratory of the Research Center of Pediatrics and Pediatric Surgery under the Ministry of Public Health of the Republic of Kazakhstan using the laser flow cytometry with application of monoclonal antibodies made by Status (Sorbent LLC, Podolsk, the Russian Federation) using dual labelling.

Samples were analyzed with the help of a flow cytofluorometer FacsCalibur (Becton Dickenson) in the CellQuest software.

The following panels of antibodies were used in the study:

- CD45/CD14 (for identification of populations of lymphocytes and identification of a lymphocytic window based on the small angle and side scatter);

- IgG1/IgG2 (to control nonspecific bonding of lymphocytes with anti-human anti-bodies and identification of negative bodning based on flourescency of the lymphocytic window);

- $\mathrm{CD} 3 / \mathrm{CD} 19$ (to determine the content of T- and B-lymphocytes, respectively);

- $\quad$ CD4/CD8 (to determine the quantity of T-helpers and T-cytotoxic lymphocytes);

- $\mathrm{CD} 3 / \mathrm{HLA}-\mathrm{DR}$ (to determine the quantity of activated T-lymphocytes);

- $\mathrm{CD} 3 / \mathrm{CD} 16+56+$ (to determine the content of natural killers).

The study of anti-inflammatory cytokines was conducted in the immunological laboratory of the Research Center of Obstetrics, Gynecology and Perinatology under the Ministry of Public Health 
of the Republic of Kazakhstan. The corresponding testing system for ELISA analysis conducted by Cytokin LLP (Saint-Petersburg, the Russian Federation) was used for determination of IL-6. The following testing systems were used for determination of INF $\gamma$, TNF $\alpha$ for ELISA analysis Gamma-Interferon-IFA-BEST and alpha-TNF- IFA-BEST produced by Vector Best CJSC/Koltsovo, the Novosibirsk Oblast, the Russian Federation.

Statistical processing of the material was performed using the licensed application software StatSoft Statistica v 6.0 and Microsoft Excel XP and generally accepted variation statistics methods with calculation of the arithmetical mean $(\mathrm{M})$, moderate error $(\mathrm{m})$, the confidence interval was accepted within 95\% $(\mathrm{P}<0.05)$ using Student's t-test $(\mathrm{t})$, at that, recommendations for medical, biological and mathematical studies were taken into account.

The correlation coefficient $r$ was used to study the relationship between the indicators.

The material was collected in the period from 2006 until 2010 in the pediatric gynecologist's consulting room at the State Public Utility Enterprise "Municipal Polyclinic No. 11" and the State Public Utility Enterprise "Municipal Human Reproduction Center" in Almaty.

We selected 104 patients with nonspecific vulvovaginitis aged 11 to 18 at last birthday, menstruating, with no sexual activities and 20 healthy patients of the same age for control. They included patients who came with different complaints about the genitals, by referral of the local pediatrician, the adolescent physician or in the course of preventive examination at schools.

- Group I (healthy, control) - 20 patients

- Group II (subacute nonspecific vulvovaginitis) - 62 patients

- Group III (acute nonspecific vulvovaginitis) - 42 patients.

The population of patients was initially specific, i.e. with nonspecific vulvovaginitis which confirmed the correct methodology for selection of the groups.

Selection criteria for Groups II and III were absence of systemic or local anti-bacterial therapy within one month prior to the visit, clinical, laboratory confirmation of the nonspecific vulvovaginitis diagnosis, exclusion of STIs, foreign objects in the vagina, consent of patients' mothers to be included in the study, research and treatment.

\section{Results of the Research}

The clinical pattern of subacute and acute nonspecific vulvovaginitis in the survey of 104 patients was represented by vulvitis and urethritis.

The most frequent complaint in the acute course of the disease was redness in the area of the

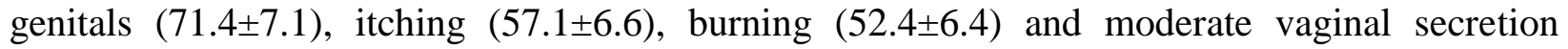
(47.6 \pm 6.2$)$ and abundant vaginal secretion (45.2 \pm 6.1$)$. Hyperemia (92.9 \pm 7.5$)$ and swollen vaginal vestibule mucosa $(71.4 \pm 7.1)$ were found during the examination most often. 
In case of subacute vulvovaginitis, the main complaint was itching (50.0 \pm 5.9$)$, burning $(40.3 \pm 5.5)$ and pain in the area of external genitals (33.9 \pm 5.2$)$. During examination, hyperemia of the vaginal vestibule was found in $80.6 \pm 6.4$ and its swelling was observed in $48.4 \pm 5.8$.

The clinical pattern of the acute course of the disease demonstrate moderate vaginal secretion

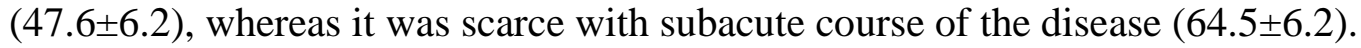

Attention was drawn to the fact that the patients of both groups had pathological secretions from the genitals for a number of weeks or more, and sought medical advice only after they started feeling itching, burning and discomfort in the area of the genitals.

During the examination, attention was drawn to the dissonance of the level of inflammatory symptoms expressed in the subacute course.

Objectively typical symptoms of subacute vulvovaginitis were isolated hyperemia of internal surfaces of labia minora and majora, the vaginal vestibule, as well as injected vulva vessels which witnessed a long inflammatory process.

Absence of subjective feelings, limitation of an inflammatory process to inflammation of glands and urethral lacunes, stagnant hyperemia and swollen vaginal vestibule confirmed the subacute character of vulvovaginitis.

Table 1: Indicators of the immune status and the phagocytic function of the vaginal secretion in adolescent girls surveyed $(\mathrm{M} \pm \mathrm{m})$

\begin{tabular}{|c|c|c|c|}
\hline Indicators & $\begin{array}{c}\text { Group I } \\
(\mathbf{n}=\mathbf{2 0})\end{array}$ & $\begin{array}{c}\text { Group II } \\
(n=62)\end{array}$ & $\begin{array}{c}\text { Group III } \\
(n=42)\end{array}$ \\
\hline CD3+(\%) & $64.5 \pm 0.3$ & $59.32 \pm 1.9^{*}$ & $69.2 \pm 6.4$ \\
\hline $\mathrm{CD} 4+(\%)$ & $53.9 \pm 1.0$ & $49.4 \pm 5.1$ & $53.0 \pm 8.1$ \\
\hline $\mathrm{CD} 8+(\%)$ & $23.2 \pm 0.7$ & $20.8 \pm 2.7$ & $22.0 \pm 5.3$ \\
\hline $\mathrm{CD} 20+(\%)$ & $15.3 \pm 0.7$ & $12.4 \pm 0.6^{*}$ & $14.9 \pm 4.1$ \\
\hline $\mathrm{IFN} \gamma(\mathrm{pg} / \mathrm{ml})$ & $11.02 \pm 0.74$ & $12.49 \pm 6.49$ & $17.32 \pm 12.2$ \\
\hline$T N F \alpha(\mathrm{pg} / \mathrm{ml})$ & $4.48 \pm 0.57$ & $3.99 \pm 0.70$ & $4.14 \pm 1.7$ \\
\hline IL6(pg/ml) & $22.62 \pm 1.80$ & $38.24 \pm 3.22$ & $36.5 \pm 26.7$ \\
\hline Spontaneous phagocytic index, $\%$ & $22.4 \pm 5.4$ & $35.8 \pm 5.8$ & $47.2 \pm 15.2$ \\
\hline Spontaneous phagocytic number & $8.0 \pm 0.2$ & $5.9 \pm 1.4$ & $6.7 \pm 1.5$ \\
\hline Pyrogenal-induced phagocytic index, $\%$ & $36.3 \pm 4.7$ & $48.8 \pm 8.4$ & $50.0 \pm 10.0$ \\
\hline Pyrogenal-induced phagocytic number & $10.0 \pm 0.3$ & $6.6 \pm 1.2 *$ & $8.7 \pm 0.7$ \\
\hline Spontaneous nitroblue tetrazolium, $\%$ & $24.5 \pm 13.0$ & $10.1 \pm 4.12$ & $14.2 \pm 6.2$ \\
\hline Pyrogenal-induced nitroblue tetrazolium, \% & $44.1 \pm 5.7$ & $12.4 \pm 4.9 *$ & $32.3 \pm 2.3 * * *$ \\
\hline \multicolumn{4}{|c|}{$\begin{array}{l}* \text { The difference is reliable at } \mathrm{P} \leq 0.05 \text { between Group I and Group II } \\
* * \text { The difference is reliable at } \mathrm{P} \leq 0.05 \text { between Group I and Group III } \\
* * * \text { The difference is reliable at } \mathrm{P} \leq 0.05 \text { between Group II and Group III }\end{array}$} \\
\hline
\end{tabular}


It was established while analyzing the results of the immunological status that secondary immune deficiency may occur with subacute form of the disease and it lacks in case of the acute form of the disease.

The phagocytic function of the local secretion is satisfactory in case of acute nonspecific vulvovaginitis, but reduction of the bactericidal activity of vaginal secretion is observed in case of subacute vulvovaginitis on the background of the satisfactory absorbing function.

Table 2: Occurrence of increased cytokines in adolescent girls surveyed

\begin{tabular}{|l|l|l|l|}
\hline Indicators $(\mathbf{p g} / \mathbf{m l})$ & Group I $(\mathbf{n = 2 0})$ & Group II (n=62) & Group III $(\mathbf{n = 4 2})$ \\
\hline IFN $\gamma$ & 0 & $15.0 \pm 8.0^{*}$ & $23.8 \pm 6.6^{* *}$ \\
\hline$T N F \alpha$ & $10.0 \pm 6.7$ & $20.0 \pm 8.9$ & $21.4 \pm 6.3$ \\
\hline IL6 & 0 & $20.0 \pm 8.9 *$ & $14.3 \pm 5.4 * *$ \\
\hline$*$ The difference is reliable at $\mathrm{P} \leq 0.05$ between Group I and Group II \\
$* *$ The difference is reliable at $\mathrm{P} \leq 0.05$ between Group I and Group III \\
\hline
\end{tabular}

The study of the cytokine status showed that average indicators of the cytokine profile of the peripheral blood in all studied groups reliably did not differ from average indicators of the control group due to a wide range of indicators.

That is why, further analysis of cytokine production was conducted based on the percentage of higher and high indicators.

High production of INF $\gamma$, TNF $\alpha$ and IL-6 was not observed in the control group. Increased TNGF $\alpha$ production was recorded in $10 \%$ of the surveyed patients.

Increased IFN $\gamma$ production was observed in $15 \%$ of the surveyed patients in case of the subacute course of nonspecific vulvovaginitis, at that an adequately high (4 times higher) content was recorded only in one patient (5\%). The increased level of TNFa production was noted in $20 \%$, at that no one demonstrated high production (4 times higher). At the same time, increased IL-6 production was noted in $20 \%$. It should be noted that high IL-6 production (5-13 times higher) was noted in $15 \%(3 / 20)$. When comparing the increased content occurrence indicators with the control group, the increased IFN $\gamma$ and IL-6 production was reliably recorded more often in the group with subacute nonspecific vulvovaginitis. But, adequate cytokine explosion with activation of antiinfectious immunity was observed only in $1 / 6$ of the cases.

Increased TNF $\alpha$ production was observed in $23.8 \%$ of the surveyed patients with acute nonspecific vulvovaginitis. At that, adequately high (4 times higher) content was recorded in $3 / 42(7.1 \%)$ of the surveyed patients. The increased level of TNF $\alpha$ production was noted in 21.4 $\%$ of the surveyed patients, at that no one demonstrated high production (4 times higher). The increased IL-6 production was noted in $14.3 \%$, at that high production was recorded in $4.7 \%$ of the patients. When comparing the increased content occurrence indicators with the control group, the increased IFN $\gamma$ and IL-6 production was reliably $(\mathrm{P} \leq 0.05)$ recorded more often in the group with acute vulvovaginitis. 
The conducted study showed that increased production of anti-inflammatory INF $\gamma$ cytokine is observed in girls and adolescents with acute nonspecific vulvovaginitis compared to the subacute course of the disease, though no adequately high production of this cytokine is practically observed in both cases. The obtained data indicate the suppression of both the cell and humoral anti-inflammatory immunity. IL-6 is responsible for the specificity and the adequacy of immunological reactions. This fact is connected primarily with the presence of multidirectional pathological changes in the immunity system.

\section{Conclusions and Recommendations}

Thus, the increased production of IFN $\gamma$ anti-inflammatory cytokine occurs almost 1.6 times more often with acute nonspecific vulvovaginitis compared to subacute nonspecific vulvovaginitis which indicates the presence of direct dependence of the level of activity of anti-inflammatory cytokines on the clinical course of the inflammation process. Adequately high production of this cytokine is practically not observed in both forms of progression of nonspecific vulvovaginitis.

The obtained data indicate the suppression of both the cell and humoral anti-inflammatory immunity, as TNF- $\alpha$ possesses the function of a co-stimulator for T-cell activation and activation of mononuclear phagocytes, promotes the anti-body formation with B-cells, IL6 is responsible for specificity and adequacy of immunological reactions. This fact is connected primarily with the presence of multidirectional pathological changes in the immunity system. Patients with nonspecific vulvovaginitis need to evaluate both the immune and cytokine status. The identified deviations must be taken into account when performing the immune system correction.

\section{References}

[1] Kokolina V.F. 2014. Urogenital infections at children and teenagers. Diagnostics and treatment. The management for doctors. Moscow, ID of "MEDPRAKTIKA-M", pp:92.

[2] Uvarova E.V., Sultanova F.Sh., 2002. The vagina as a microecosystem is normal also at inflammatory processes of genitalias of various etiology (the review of literature). Consilium Medicum, gynecology, 04: 189-196.

[3] Vovk I.B., Bilochenko AM, 2004. Vulvovaginitis in children: a modern view of the problem. Pediatrics, Obstetrics and Gynecology, 4: 94-97.

[4] Slanting S.L., Moses V.G.,2012. Diagnostics and treatment of a vulvovaginitis at girls. Mother and the child in Kuzbass, 4: 3-6.

[5] Ramírez-Santos A, Pereiro M Jr, Toribio J., 2008. Recurrent vulvovaginitis: diagnostic assessment and therapeutic management. Article in Spanish. Actas Dermo-Sifiliográficas, Apr; 99 (3): 190-8.

[6] Uvarova E.V., Latypova N.H., Kumykova Z.H., 2008. A role of anatomic and physiological features of a vagina and a neck of uterus at teenage girls in development of inflammatory diseases of lower parts of a genital tract. Genesial health of children and teenagers, 1: 34-44.

[7] Simbirtsev A. S., 2002. Cytokines-new system of a regulation of protective reactions of an organism. Cytokines and inflammation, 1:9-16.

[8] Haitov R.M., Pinegin B.V., 2000. Modern ideas of protection of an organism against an infection. Immunology, 1:61-64.

[9] Zheleznikova G.F., 2009. Cytokines as predictors of a current and outcome of infections. Cytokines and inflammation, 8(1):10-17 
[10] Demyanov A.V., Kotov A.Yu., Simbirtsev A. S., 2003. The diagnostic value of a research of levels of cytokines in clinical practice. Cytokines and inflammation, 2(3): 20-35

[11] Kashkin KP, 2004. Immunological studies in the clinic of infectious diseases. News of Applied Immunology and Allergology, 8: 1-10

[12] Ranneva L.K., Hadartseva K.A., 2016. Early diagnostics of a nonspecific vulvovaginitis. Prospects of high school science: to the 25 anniversary of high school medical education and science of Tula region (the collection of works), 1. pp:114-121

[13] Ziyadullayev U.H., 2013. The Tsitokinovy profile at a kandiidozny vulvovaginitis at teenage and early age. Kazan medical magazine. 94(6):817-820

[14] Sennikov S.V., A.N. Drag-net, 2005. Methods of definition of cytokines. Cytokines and inflammation. 4(1):22-27.

[15] Kramar L.V., Karpukhina O.A., Hlyninayu. Lake, 2011. Modern opportunities of immunomodulatory and immunocorrective therapy at infectious diseases of children. Medicinal messenger. 6(3)(43): 15-23.

*Corresponding author.

E-mail address: dr.smaylova@ mail.ru/alm_kurmanova@mail.ru 